\title{
Molecular analysis using DHPLC of cystic fibrosis: increase of the mutation detection rate among the affected population in Central Italy
}

\author{
Maria Rosaria D'Apice1, Stefano Gambardella' ${ }^{1}$, Mario Bengala², \\ Silvia Russo ${ }^{1}$, Anna Maria Nardone ${ }^{2}$, Vincenzina Lucidi ${ }^{3}$, \\ Federica Sangiuolo ${ }^{1,2}$ and Giuseppe Novelli*1,2
}

Address: ${ }^{1}$ Dipartimento di Biopatologia, Università di Roma Tor Vergata, Roma, Italy, ${ }^{2}$ Azienda Ospedaliera Universitaria Policlinico di Tor Vergata, Roma, Italy and ${ }^{3}$ Ospedale Pediatrico Bambino Gesù, Roma, Italy

Email: Maria Rosaria D'Apice - d.apice@med.uniroma2.it; Stefano Gambardella - stefanogamb@libero.it;

Mario Bengala - mario.bengala@ptvonline.it; Silvia Russo - silviarusso@yahoo.it; Anna Maria Nardone - annamaria.nardone@ptvonline.it; Vincenzina Lucidi - lucidi@opbg.net; Federica Sangiuolo - sangiuolo@med.uniroma2.it; Giuseppe Novelli* - novelli@med.uniroma2.it

* Corresponding author

Published: 14 April 2004

BMC Medical Genetics 2004, 5:8

This article is available from: http://www.biomedcentral.com/I47/-2350/5/8

(C) 2004 D'Apice et al; licensee BioMed Central Ltd. This is an Open Access article: verbatim copying and redistribution of this article are permitted in all media for any purpose, provided this notice is preserved along with the article's original URL.
Received: 26 November 2003

Accepted: 14 April 2004

\begin{abstract}
Background: Cystic fibrosis (CF) is a multisystem disorder characterised by mutations of the CFTR gene, which encodes for an important component in the coordination of electrolyte movement across of epithelial cell membranes. Symptoms are pulmonary disease, pancreatic exocrine insufficiency, male infertility and elevated sweat concentrations. The CFTR gene has numerous mutations ( $>1000)$ and functionally important polymorphisms $(>200)$. Early identification is important to provide appropriate therapeutic interventions, prognostic and genetic counselling and to ensure access to specialised medical services. However, molecular diagnosis by direct mutation screening has proved difficult in certain ethnic groups due to allelic heterogeneity and variable frequency of causative mutations.
\end{abstract}

Methods: We applied a gene scanning approach using DHPLC system for analysing specifically all CFTR exons and characterise sequence variations in a subgroup of CF Italian patients from the Lazio region (Central Italy) characterised by an extensive allelic heterogeneity.

Results: We have identified a total of 36 different mutations representing $88 \%$ of the CF chromosomes. Among these are two novel CFTR mutations, including one missense (HI99R) and one microdeletion (4I67delCTAAGCC).

Conclusion: Using this approach, we were able to increase our standard power rate of mutation detection of about II\% (77\% vs. $88 \%)$.

\section{Background}

Cystic fibrosis (OMIM \#219700) is one of the most com- mon genetic diseases in Caucasians with a frequency of $1 /$ $3500[1,2]$. Affected children have two mutations in the 
CFTR gene (CFTR/ABCC7, OMIM \#602421), a gene that contains 27 exons encompassing approximately $180 \mathrm{~kb}$ of DNA on chromosome 7q31.2. CFTR protein is a $\mathrm{Cl}^{-}$channel, which regulates ion flow across the apical membrane of airway, gastrointestinal and reproductive epithelia, and of sweat glands and pancreatic ducts [3-6]. Over 1000 mutations have been described in the Cystic Fibrosis Mutation Consortium [7], mutations that are clustered in six different classes including defective CFTR biosynthesis, defective protein processing, alteration in CFTR regulation, disruption of the pore activity, alteration of CFTR localisation, and genesis of unstable CFTR [8]. The most common mutation is a deletion of three nucleotides (1652delCTT) that leads to a loss of a phenylalanine residue at position 508 (delF508) of the gene product. This is responsible for approximately two thirds of all CF chromosomes, with a clear Northwest to Southeast gradient in its frequency in the human population across Europe [9]. There is a core of 25 "less common" mutations designated by the CF Steering Committee in 2001 that occur with a European frequency of $0.1 \%$ or greater. The remainder of the mutations are termed "rare", being found in only one or few individuals [9]. The spectrum of CFTR-associated phenotypes is quite variable, going from classic CF to mild monosymptomatic presentations, like idiopathic pancreatitis, chronic rhinosinusitis, nasal polyposis, asthma, disseminated bronchiectasis and congenital bilateral absence of the vas deferens (CBAVD) [10]. Some mutations are clearly associated with a mild phenotype (with pancreatic insufficiency and a life expectancy over 50 years) [8]. Other attempts to link mutations in CFTR to disease severity have not been successful, suggesting an influence of non-CFTR gene modifiers and environmental factors [11].

CF diagnosis is based on defined phenotypic criteria, on CF history in the family and/or a positive test for hypertrypsinaemia (IRT) in the neonatal period. In the majority of cases, the diagnosis of CF is confirmed by elevated ( $>60$ $\mathrm{nmol} / \mathrm{l}$ ) sweat chloride concentrations, and by a raised electrical potential difference (NPD) across the nasal epithelium. Molecular diagnosis is based on CFTR mutation screening. However, extensive allelic heterogeneity frequently impairs the rate of detection and therefore the value of the genotypic diagnosis. Several mutation scanning methods have been applied to the detection of sequence variations in the entire coding region of CFTR such as heteroduplex analysis and restriction enzyme analysis [12], single-strand conformation polymorphism analysis (SSCP) [13], and the DGGE method [14,15]. Recently, two different groups have used the DHPLC technology to detect CF alleles [16-18]. We analysed a cohort of CF patients clinically defined from Central Italy (an area characterized by an high allelic heterogeneity) [9] for the presence of CFTR mutations by using this technique to optimize mutation detection. The results presented here not only provide a comprehensive spectrum of the molecular basis of CF in the Central Italy, but also underscore the need for multi-approach screening of CFTR gene in heterogeneous populations to reach appreciable levels of detection rates.

\section{Methods \\ Patients}

All CF patients came from the population of children born in Central Italy (diagnosis performed using standard clinical criteria at Ospedale Bambino Gesù, Roma). Samples were included for DHPLC screening on the basis of presentation of family history and/or abnormal sweat tests. All 290 samples were analysed for the 29 common mutations by INNO-LiPA CFTR12 and CFTR17+Tn assays (Innogenetics NV, Zwijndrecht, Belgium) as part of the routine testing service provided at the centre. During the course of the study, 117 samples were shown to have only one or none of the 29 common mutations tested and were selected for further investigation. DNA from healthy subjects was randomly chosen as controls. Their DNA was sequenced and the entire CFTR gene sequence was confirmed to be wild-type with respect to CFTR. Genomic DNA was isolated from peripheral blood leukocytes using a salting-out protocol.

\section{DNA amplification}

Coding regions and intron/exon boundaries of the CFTR gene were amplified in 29 reactions using primers described by Le Marechal et al. [17]. A novel primer design was only required for exons $6 \mathrm{~b}$ and 9 to improve the PCR sensitivity. Fifty to $100 \mathrm{ng}$ of genomic DNA from different patients were used for the PCR reaction. Amplification was performed in a $25 \mu \mathrm{l}$ reaction volume containing 0.2 $\mathrm{mM}$ each of primers, $200 \mu \mathrm{M}$ dNTPs, $1 \mathrm{X}$ reaction buffer (10 mM Tris $\mathrm{HCl} \mathrm{pH} 8.3,50 \mathrm{mM} \mathrm{KCl}, 2.5 \mathrm{mM} \mathrm{MgCl}_{2}$ ) and 1.25 U AmpliTaq Gold ${ }^{\mathrm{TM}}$ DNA polymerase (PE Applied Biosystems, Foster City, CA) by a Gene Amp PCR System 9700 (PE Applied Biosystems, Foster City, CA). PCR amplification was carried out at $94^{\circ} \mathrm{C}$ for $10 \mathrm{~min}$ and then cycled 35 times at $94^{\circ} \mathrm{C}$ for $40 \mathrm{sec}, 57^{\circ} \mathrm{C}$ or $61^{\circ} \mathrm{C}$ for 40 sec and $72^{\circ} \mathrm{C}$ for $1 \mathrm{~min}$, followed by $7 \mathrm{~min}$ at $72^{\circ} \mathrm{C}$ in the final cycle. Amplicons were checked by agarose gel electrophoresis before DHPLC analysis, to make sure that only the specific product was amplified.

\section{DHPLC analysis}

DHPLC analysis was carried out on a WAVE DNA fragment analysis system (Transgenomic ${ }^{\mathrm{TM}}$, Crewe, UK) equipped with a DNASep ${ }^{\circledR}$ Column (Transgenomic ${ }^{\mathrm{TM}}$, Crewe, UK). PCR products was denatured for $5 \mathrm{~min}$ at $95^{\circ} \mathrm{C}$ before being gradually reannealed by decreasing sample temperature from 95 to $65^{\circ} \mathrm{C}$ over a period of 30 min to enable the formation of heteroduplexes. DHPLC analysis was carried out at a flow-rate of $0.9 \mathrm{ml} / \mathrm{min}$ and 
buffer B (0.1 M TEAA, 25\% acetonitrile), with a gradient increase of $2 \%$ per min for $4 \mathrm{~min}$. The start and end concentration of buffer B and oven temperature for optimal heteroduplex separation have previously been described [17].

\section{Data analysis}

Four wild-type samples were always used as negative controls, to ensure that a normal homoduplex profile was reproducibly obtained with regard to retention time and peak profile. Chromatograms were overlaid with one from a wild-type. Samples with extra peaks (one, two or three more), or with a difference in peak appearance, were scored as positive.

\section{Sequence analysis}

Samples showing abnormal elution profile were reamplified from genomic DNA. PCR products were purified with GeneDia Seq-Prep Kit and were sequenced in both directions using CEQ ${ }^{\mathrm{TM}} 2000$ (Beckman Coulter Inc. USA).

\section{Results}

CF patients were firstly screened using a standard panel of 29 different CF mutations (INNO-LiPA CFTR12 and CFTR17+Tn). Of these, 173 were homozygous or compound heterozygous $(+/+), 105$ were positives for only one mutations (+/-) and 12 were negative for both mutations (-/-). The unknown alleles were screened by DHPLC technology. In order to set-up elution conditions and profiles of known mutations not included in the INNO-LiPA kits, we ran amplicons obtained from DNAs carrying 10 rare CFTR mutations previously found and identified by sequencing in compound heterozygote CF patients from an area of Central Italy [19]. These mutations included S4X (143 C to A), exon 1; S42F (257 C to T), exon 2; R117L (482 G to T), exon 4; S549R (1779 T to G), exon 11 ; 3667ins4, exon 19; A1006E (3149 C to A), exon17a; L1065P (3326 T to C), R1066C (3328 C to T), L1077P (3362 $\mathrm{T}$ to $\mathrm{C})$, exon $17 \mathrm{~b}$. DHPLC profiles are shown in Figure 1. In contrast to the normal control that shows a single peak of homoduplex DNA, all samples with previously identified mutations produced chromatograms of a different shape. New primers were synthesised only for exons $6 \mathrm{~b}$ and 9, and they annealed to the coding sequence (Table 1). DHPLC conditions were set up according to WAVEmaker software (Transgenomic) and the DHPLC Melt program (Table 1) [20]. The complete spectrum of mutations detected in the sample is reported in Table 2. A total of 36 different mutations, including 22 missense, 4 nonsense, 6 micro insertion/deletion and 4 splicing mutations were detected. Only six mutations have a frequency $>1 \%$, which account for $77.5 \%$ of the total CF chromosomes. Nineteen mutations have frequencies between $0.9 \%$ and $0.4 \%$, and cover $8.36 \%$ of the CF chromosomes. Finally, 11 mutations were found only once in the population, increasing the proportion of the characterised CF alleles by $1.87 \%$ (data not shown). Among these mutations, we have identified and characterised in the Italian population two novel mutations in two affected children: H199R and 4167delCTAAGCC. An abnormal DHPLC pattern in exon 6 a due to the nucleotide change A to $G$ at position 728 of CFTR determines the missense mutation H199R that falls into the transmembrane domain, TM1. This CF mutation was identified in a patient who carries the N1303K (4041 C to G) mutation on the maternal CF chromosome. H199R mutation, to our knowledge, has been detected in a single CF chromosome in a population in Brittany [7]. The other two mutations that affect the same codon are described: H199Y (727 C to T), found in a German CF patient heterozygous for delF508 and who exhibits only mild pancreatic symptoms and borderline sweat chloride values, and H199Q (729 T to G). The microdeletion 4167 delCTAAGCC in exon 22 was identified by DHPLC analysis in a CF patient who presents the L1065P (3326 T to C) mutation on the maternal chromosome. This mutation leads to a premature stop codon, resulting in the deletion of 90 carboxyterminal amino acid residues. Consequently, the NBF2 intracellular domain, which constitutes a CFTR ATP binding domain, is lost. These two novel mutations were not found in a group of 100 healthy controls. Furthermore, in both cases, no other alterations were observed after the complete screening of all the coding and flanking regions of CFTR gene. DHPLC analysis also revealed 8 DNA sequence variations (Table 3 ). In some cases these variations co-segregated with pathogenic CF mutations within the same fragment, resulting in an altered DHPLC profile. Finally, in a single CF patient, we detected two different mutations [G542X (1756 G to T) and S549R (1779 T to G)] in the same exon 11-derived DNA amplicon, which showed a peculiar DHPLC pattern, different from that observed when only one of these mutations was present (data not show).

Overall, these results revealed a detection rate of $88 \%$, increasing the standard level of detection by $~ 11 \%$.

\section{Discussion}

Prior to complete gene analysis $~ 77 \%$ of the mutant alleles could be detected by screening with various commercially available mutation panels. CFTR gene analysis by DHPLC presented here allowed identification of an additional $11 \%$ of mutant alleles, including nine rare mutations and 2 novel ones, underlying the high mutational heterogeneity for CF in this Italian population. The two novel mutations identified could be pathogenic because they determine significant alterations in the protein. H199R has a substitution of a conserved amino acid crucial in the TM1 domain, while the other, a 7bp-deletion, 

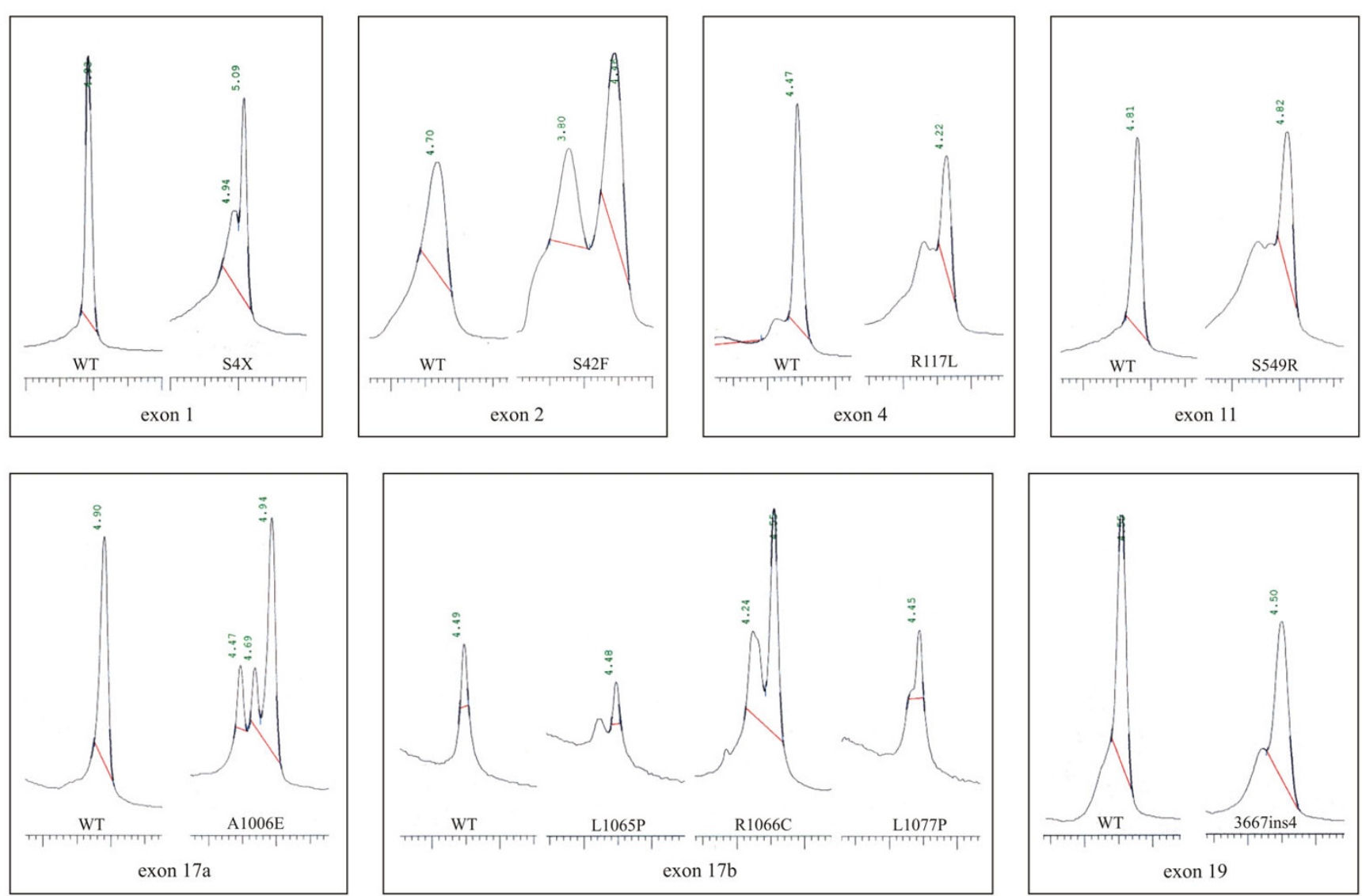

Figure I

DHPLC chromatograms corresponding to nine different CFTR mutations from heterozygous patients compared to a normal sample (WT). The profiles of the mutants show extra peaks or a shoulder and are easily distinguished from profiles of the wild type, which shows a single peak.

Table I: Primers and DHPLC (oven temperature, gradient) analysis conditions for $6 \mathrm{~b}$ and 9 exons of the CFTR gene

\begin{tabular}{lllll}
\hline exon & Primer $\mathbf{5}^{\prime} \rightarrow \mathbf{3}^{\prime}$ & Amplicon length & Oven temp $\left({ }^{\circ} \mathbf{C}\right)$ & \% B buffer start/end \\
\hline $6 b$ & $\begin{array}{l}\text { F - CAGAGATCAGAGAGCTGGG } \\
\text { R - GAGGTGGAAGTCTACCATGA }\end{array}$ & 323 & 56 & $55 / 63$ \\
9 & $\begin{array}{l}\text { F - GGGATTGGGGATTATTTG } \\
\text { R - TCTCCAAAAATACCTTCCAG }\end{array}$ & 279 & 55 & $54 / 62$ \\
\hline
\end{tabular}

introduces a premature STOP codon, resulting in a truncated protein.

Mutation screening of newborns clinically suspected of having cystic fibrosis can contribute to the confirmation of diagnosis, and in some instances may help to predict the severity of the disease. This can lead to early treatment to retard irreversible tissue damage and ensure the highest possible quality of life for these individuals. The level of detection is therefore important, and this will depend on the sensitivity of the method used. Routine methods, i.e. INNO-LiPA CFTR assay, include a bias since they are based on a selection of known mutations, established on the basis of mutations frequently occurring in North Caucasians. Due to the large number of mutations found in the CFTR gene and their variable frequency among differ- 
Table 2: CF mutations identified in cohort of 290 patients from the Central Italy

\begin{tabular}{|c|c|c|c|c|c|}
\hline Mutation & Nucleotide change & Exon/intron & $\mathbf{N}$ & $\%$ & Method \\
\hline delF508 & 1652delCTT & 10 & 328 & 56.36 & INNO-LiPA, DHPLC \\
\hline NI303K & $404 \mid C$ to $G$ & 21 & 51 & 8.76 & INNO-LiPA, DHPLC \\
\hline G542X & I $756 \mathrm{G}$ to $\mathrm{T}$ & 11 & 42 & 7.21 & INNO-LiPA, DHPLC \\
\hline WI $282 X$ & $3978 \mathrm{G}$ to $\mathrm{A}$ & 20 & 15 & 2.60 & INNO-LiPA, DHPLC \\
\hline S549R & I $779 \mathrm{~T}$ to $\mathrm{G}$ & 11 & 8 & 1.37 & DHPLC \\
\hline $621+1 G-T$ & $62 I+1 \mathrm{G}$ to $\mathrm{T}$ & Intron 4 & 7 & 1.20 & INNO-LiPA, DHPLC \\
\hline I7I7-IG-A & $1717-1 \mathrm{G}$ to $\mathrm{A}$ & Intron 10 & 5 & 0.86 & INNO-LiPA, DHPLC \\
\hline G85E & $386 \mathrm{G}$ to $\mathrm{A}$ & 3 & 4 & 0.69 & INNO-LiPA, DHPLC \\
\hline R553X & $1789 \mathrm{C}$ to $\mathrm{T}$ & 11 & 4 & 0.69 & INNO-LiPA, DHPLC \\
\hline HI39R & $548 \mathrm{~A}$ to $\mathrm{G}$ & $6 a$ & 3 & 0.51 & DHPLC \\
\hline R347P & $1172 \mathrm{G}$ to $\mathrm{C}$ & 7 & 3 & 0.51 & INNO-LiPA, DHPLC \\
\hline LI065P & $3326 \mathrm{~T}$ to $\mathrm{C}$ & $17 \mathrm{~b}$ & 3 & 0.51 & DHPLC \\
\hline LI077P & $3362 \mathrm{~T}$ to $\mathrm{C}$ & $17 \mathrm{~b}$ & 3 & 0.51 & DHPLC \\
\hline S4X & $143 \mathrm{C}$ to $\mathrm{A}$ & I & 2 & 0.34 & DHPLC \\
\hline $\mathrm{DIIOH}$ & $460 \mathrm{G}$ to $\mathrm{C}$ & 4 & 2 & 0.34 & DHPLC \\
\hline R334W & $1132 \mathrm{C}$ to $\mathrm{T}$ & 7 & 2 & 0.34 & INNO-LiPA, DHPLC \\
\hline M348K & $1175 \mathrm{~T}$ to $\mathrm{A}$ & 7 & 2 & 0.34 & DHPLC \\
\hline 1259insA & 1259 ins $A$ & 8 & 2 & 0.34 & DHPLC \\
\hline S549N & $1778 \mathrm{G}$ to $\mathrm{A}$ & 11 & 2 & 0.34 & DHPLC \\
\hline L558S & $1805 \mathrm{~T}$ to $\mathrm{C}$ & 11 & 2 & 0.34 & DHPLC \\
\hline $2183+A A-G$ & $2183 A$ to $G$ and $2184 \operatorname{del} A$ & 13 & 2 & 0.34 & INNO-LiPA, DHPLC \\
\hline $2789+5 G-A$ & $2789+5 \mathrm{G}$ to $\mathrm{A}$ & Intron $14 b$ & 2 & 0.34 & INNO-LiPA, DHPLC \\
\hline RI066C & $3328 \mathrm{C}$ to $\mathrm{T}$ & $17 b$ & 2 & 0.34 & DHPLC \\
\hline 3667ins4 & 3667ins TCAA & 19 & 2 & 0.34 & DHPLC \\
\hline $\mathrm{S} 42 \mathrm{~F}$ & $257 \mathrm{C}$ to $\mathrm{T}$ & 2 & 2 & 0.34 & DHPLC \\
\hline $\mathrm{RII7L}$ & $482 \mathrm{G}$ to $\mathrm{T}$ & 4 & 1 & 0.17 & DHPLC \\
\hline $\mathrm{HI} 99 \mathrm{R}$ & 728 A to $G$ & $6 a$ & i & 0.17 & DHPLC \\
\hline R334L & $1133 \mathrm{G}$ to $\mathrm{T}$ & 7 & I & 0.17 & DHPLC \\
\hline T338I & $1145 \mathrm{C}$ to $\mathrm{T}$ & 7 & I & 0.17 & DHPLC \\
\hline G55ID & $1784 \mathrm{G}$ to $\mathrm{A}$ & 11 & I & 0.17 & INNO-LiPA, DHPLC \\
\hline Q552X & $1786 \mathrm{C}$ to $\mathrm{T}$ & 11 & i & 0.17 & INNO-LiPA, DHPLC \\
\hline D6I4G & $1973 A$ to $G$ & 13 & I & 0.17 & DHPLC \\
\hline Al006E & $3149 \mathrm{C}$ to $\mathrm{A}$ & $17 \mathrm{a}$ & I & 0.17 & DHPLC \\
\hline $4016 \mathrm{ins} T$ & 4016 ins $T$ & 21 & i & 0.17 & DHPLC \\
\hline 4040delA & $4040 \mathrm{del} \mathrm{A}$ & 21 & I & 0.17 & DHPLC \\
\hline 4167 del7 & 4167 delCTAAGCC & 22 & i & 0.17 & DHPLC \\
\hline Detected & & & 511 & 88.10 & \\
\hline Unknown & & & 69 & 11.90 & \\
\hline Total & & & 580 & 100.00 & \\
\hline
\end{tabular}

$N=$ number of $C F$ chromosomes; \% = frequency.

Table 3: Polymorphisms (*) identified in our cohort of CF patients by DHPLC

\begin{tabular}{ccc}
\hline Polymorphism & Nucleotide change & Exon/intron \\
\hline I25G/C & $125 \mathrm{G}$ to $\mathrm{C}$ & 5 ' UTR \\
R75Q & $356 \mathrm{G}$ to $\mathrm{A}$ & 3 \\
$875+40 \mathrm{~A} / \mathrm{G}$ & $875+40 \mathrm{~A} / \mathrm{G}$ & Intron $6 \mathrm{a}$ \\
M470V & $1540 \mathrm{~A}$ to $\mathrm{G}$ & 10 \\
T854T & $2694 \mathrm{~T}$ to $\mathrm{G}$ & $14 \mathrm{a}$ \\
T966T & $3030 \mathrm{G}$ to $\mathrm{A}$ & 15 Intron 20 \\
$4006-199 \mathrm{G} / \mathrm{A}$ & $4006-199 \mathrm{G} / \mathrm{A}$ & 21
\end{tabular}

(*) According to [7]. 
ent ethnic and racial groups, it is difficult to develop a suitable assay for all populations that covers all known mutations. With the exception of a few genetically homogeneous populations (i.e. Ashkenazi Jewish, Brittany and Quebec populations), the detection rate of CFTR mutations in heterogeneous populations varies between 88 and $90 \%[17,21-27]$. Our experience is that the DHPLC technique is useful in mutation detection in heterogeneous ethnic populations in Central and South Italy. In these populations, we have now reached a detection sensitivity similar to that observed in other Italian regions and other Mediterranean populations, where a relatively low frequency of delF508 mutation is detected.

\section{Conclusions}

In this study, we scanned the entire exonic region of the CFTR gene in genomic DNA obtained from a cohort of 290 CF patients. We were able to identify two pathogenic mutations by DHPLC technique in 211 subjects. In the remaining cases, at least a single CF allele was detected. The pattern of the elution profile for heteroduplex analysis has shown that this technique has proved to be able to distinguish the disease-causing mutations of the CFTR gene. However, in our experimental conditions, sometimes we found difficult to correlate the profile of DHPLC chromatograms with the mutation type. Consequently, further confirmation of the sequence variants by direct sequencing is necessary. Overall, DHPLC has been shown to be a reliable, sensitive, and specific screening method to rapidly detect CFTR mutations, that account for about $88 \%$ of CF alleles in our population. In addition, this semi-automated method would also be quite suitable for rapid mutational screening of unknown mutations.

These data also illustrate the need for a multi-system scanning approach. In fact, although the sensitivity was elevated, a significant rate of failure in 69 alleles analysed out of $580(11.90 \%)$ was observed. The extension of DHPLC analysis to the non-coding regions, including promoter and regulatory regions, further increases the detection rate. However, our opinion is that even extensive DHPLC analysis of the whole CFTR gene would not increase the detection rate above $95 \%$ in our population. This is because larger genomic rearrangements occurring in some CF cases, and/or technical reasons (i.e. DNA quality, primers design, fragment length), can affect DHPLC.

To maximize mutation detection, different techniques need to be employed, including DHPLC, Southern analysis, and expression studies. Recently, it has been demonstrated that the screening of large deletions by quantitative multiplex polymerase chain reaction of short fluorescent fragment (QMPSF) can improve the detection of uncharacterised CF alleles [28]. Therefore, on this basis, we recommend caution in diagnostic use of DHPLC method.

\section{Competing interests}

None declared.

\section{Authors' contributions}

MRD participated in design and coordination of the study and drafted the manuscript; SG carried out the DHPLC and sequence analysis; $\mathrm{MB}$ as a clinical geneticist providing genetic counselling and consultation to the $\mathrm{CF}$ patients and families; AMN carried out the DNA amplification; SR carried out the genomic DNA extraction; VL carried out the CF clinical diagnosis; FS participated in design and coordination of the study; GN revised the manuscript. All authors read and approved the final manuscript.

\section{Acknowledgments}

This work was supported by Italian Ministry of Health, Italian Ministry of Education, University and Research and Regione Lazio. We are extremely grateful to the patients and their families for their invaluable participation and cooperation and to TRANSGENOMIC, INC. (Omaha, NE) for the support and help in DHPLC set up.

\section{References}

I. Welsh MJ, Tsui LC, Boat TF, Beaudet AL: Cystic fibrosis. In The metabolic and molecular bases of inherited disease 7th edition. Edited by: Scriver CR, Beaudet AL, Sly WS, Valle D. McGraw Hill, New York; 1995:3799-3876.

2. Doull I: Recent advances in cystic fibrosis. Arch Dis Child 200I, 85:62-66.

3. Rommens JM, lannuzzi MC, Kerem BS, Drumm ML, Melmer G, Dean M, Rozmahel R, Cole JL, Kennedy D, Hidaka N, Zsiga M, Buchwald M, Riordan J, Tsui LC, Collins FS: Identification of cystic fibrosis gene: chromosome walking and jumping. Science 1989, 245: $1059-1065$.

4. Riordan JR, Rommens JM, Kerem BS, Alon N, Rozmahel R, Grzelczak Z, Zielenski J, Lok S, Plavsic N, Chou JL, Drumm M, lannuzi MC, Collins FS, Tsui LC: Identification of the cystic fibrosis gene: cloning and characterization of complementary DNA. Science 1989, 245: 1066-1073.

5. Kerem B, Rommens JM, Buchanan JA, Markiewicz D, Cox TK, Chakravarti A, Buchwald M, Tsui LC: Identification of cystic fibrosis gene: genetic analysis. Science 1989, 245: 1073-1080.

6. Zielenski J, Rozmahel R, Bozon D, Kerem B, Grzelczak Z, Riordan JR, Rommens J, Tsui LC: Genomic DNA sequence of the cystic fibrosis transmembrane conductance regulator (CFTR) gene. Genomics 1991, 10:214-228.

7. Cystic Fibrosis Mutation Database [http://www.genet.sickkids.on.cal cftrl].

8. Haardt M, Benharouga M, Lechardeur D, Kartner N, Lukacs GL: Cterminal truncations destabilize the cystic fibrosis transmembrane conductance regulator without impairing its biogenesis. A novel class of mutation. J Biol Chem 1999, 274:21873-21877.

9. Estivill X, Bancells C, Ramos C: Geographic distribution and regional origin of $\mathbf{2 7 2}$ cystic fibrosis mutations in European populations. The Biomed CF Mutation Analysis Consortium. Hum Mutat 1997, 10: I35-54.

10. Quinton PM: Cystic fibrosis: a disease of electrolyte transport. FASEB J 1990, 4:2709-27I7.

II. Salvatore F, Scudiero O, Castaldo G: Genotype-phenotype correlation in cystic fibrosis: the role of modifier genes. Am J Med Genet 2002, I I I:88-95.

12. Dequeker E, Cassiman JJ: Evaluation of CFTR gene mutation testing methods in 136 diagnostic laboratories: report of a large European external quality assessment. Eur J Hum Genet 1998, 6:165-175.

13. Orita M, Suzuki Y, Sekija T, Hayashi K: Rapid and sensitive detection of point mutations and DNA polymorphisms using the polymerase chain reaction. Genomics 1989, 5:874-879. 
14. Lerman LS, Silverstein K: Computational simulation of DNA melting and its application to denaturing gradient gel electrophoresis. Methods Enzymol 1987, I 55:482-50I.

15. Cremonesi L, Carrera P, Cardillo E, Fumagalli A, Lucchiari S, Ferrari M, Righetti SC, Righetti PG, Gelfi C: Optimized detection of DNA point mutations by double gradient denaturing gradient gel electrophoresis. Clin Chem Lab Med 1998, 36:959-96I.

16. Xiao W, Oefner PJ: Denaturing High-Performance Liquid Chromatography: a review. Hum Mutat 200I, I 7:439-474.

17. Le Marechal C, Audrezet MP, Quere I, Raguenes O, Langonne S, Ferec $C$ : Complete and rapid scanning of the cystic fibrosis transmembrane conductance regulator (CFTR) gene by denaturing high-performance liquid chromatography (DHPLC): major implications for genetic counselling. Hum Genet 200I, I08:290-298.

18. Ravnick-Glavac M, Atkinson A, Glavac D, Dean M: DHPLC screening of Cystic Fibrosis Gene Mutations. Hum Mutat 2002 19:374-383.

19. II sito dei laboratori di genetica molecolare CF [http://spazio web.inwind.it/laboratoriCF/].

20. DHPLC Melt Program [http://insertion.stanford.edu/melt.html]

21. Abeliovich D, Pashut Lavon I, Lerer I, Cohen T, Springer C, Avital A, Cutting GR: Screening for five mutations detects $97 \%$ of cystic fibrosis (CF) chromosomes and predicts a carrier frequency of I:29 in the Jewish Ashkenazi population. Am J Hum Genet 1992, $51: 951-956$

22. de Braekeleer M, Mari C, Verlingue C, Allard C, Leblanc JP, Simard F, Aubin G, Ferec C: Complete identification of cystic fibrosis transmembrane conductance regular mutations in the CF population of Saguenay Lac St Jean (Quebec, Canada). Clin Genet 1998, 53:44-46.

23. Casals T, Ramos MD, Gimenez J, Larriba S, Nunes V, Estivill X: High heterogeneity for cystic fibrosis in Spanish families: 75 mutations account for $\mathbf{9 0 \%}$ of chromosomes. Hum Genet 1997 1 01:365-370.

24. Claustres M, Laussel M, Desgeorges M, Giansily M, Culard JF, Razakatsara G, Demaille J: Analysis of the 27 exons and flanking regions of the cystic fibrosis gene: $\mathbf{4 0}$ different mutations account for $91.2 \%$ of the mutant alleles in Southern France. Hum Mol Genet 1993, 2:1209-1213.

25. Kanavakis E, Tzetis M, Antoniadi T, Traeger-Synodinos J, Doudounakis S, Adam G, Matsaniotis N, Kattamis C: Mutation analysis of 10 exons of the CFTR gene in Greek cystic fibrosis patients: characterization of $\mathbf{7 4 . 5 \%}$ of CF alleles including I novel mutation. Hum Genet 1995, 96:364-366.

26. Bonizzato A, Bisceglia L, Marigo C, Nicolis E, Bombieri C, Castellani C, Borgo G, Zelante L, Mastella G, Cabrini G, Gasparini P, Pignatti PF: Analysis of the complete coding region of the CFTR gene in a cohort of CF patients from North-Eastern Italy: identification of $90 \%$ of the mutations. Hum Genet 1995, 95:397-402.

27. Bombieri C, Pignatti PF: Cystic fibrosis mutation testing in Italy. Genetic Testing 200I, 5:229-233.

28. Audrezet MP, Chen JM, Raguenes O, Chuzhanova N, Giteau K, Le Marechal C, Quere I, Cooper DN, Ferec C: Genomic rearrangements in the CFTR gene: extensive allelic heterogeneity and diverse mutational mechanisms. Hum Mutat 2004, 23:343-357.

\section{Pre-publication history}

The pre-publication history for this paper can be accessed here:

http://www.biomedcentral.com/1471-2350/5/8/prepub
Publish with Biomed Central and every scientist can read your work free of charge

"BioMed Central will be the most significant development for disseminating the results of biomedical research in our lifetime. "

Sir Paul Nurse, Cancer Research UK

Your research papers will be:

- available free of charge to the entire biomedical community

- peer reviewed and published immediately upon acceptance

- cited in PubMed and archived on PubMed Central

- yours - you keep the copyright

Submit your manuscript here:

http://www.biomedcentral.com/info/publishing_adv.asp
BioMedcentral 